\title{
FORMULATION AND EVALUATION OF HERBAL OIL-BASED ITRACONAZOLE CREAM FOR FUNGAL INFECTION
}

\author{
INDER KUMAR ${ }^{1}$, BHUMIKA THAKUR ${ }^{2}$, ANKITA SHARMA ${ }^{3}$, REENA THAKUR ${ }^{4}$
}

${ }^{1}$ Department of Pharmaceutics, School of Pharmacy, Abhilashi University Chailchowk, Mandi, Himachal Pradesh, India. ${ }^{2}$ Department of Pharmaceutics, Shiva Institute of Pharmacy, Bilaspur, Himachal Pradesh, India. ${ }^{3}$ Department of Pharmaceutical Chemistry, Abhilashi College of Pharmacy, Nerchowk, Mandi, Himachal Pradesh, India. ${ }^{4}$ Department of Pharmaceutics, Himalayan Institute of Pharmacy, Kala Amb, Himachal Pradesh, India. Email: inder.93kumar@gmail.com

Received: 21 July 2020, Revised and Accepted: 25 August 2020

\section{ABSTRACT}

Objective: The current study was to formulate and to evaluate itraconazole herbal oil-based cream for fungal infection.

Methods: Six herbal oils were used for the formulation of itraconazole creams, namely, mustard oil (MO), olive oil (O0), wheat germ oil (WGO), jojoba oil (JO), tea tree oil (TTO), and combined oil (CO). Creams were formulated by the trituration method. Each herbal oils containing three different formulations of different concentrations of oils.

Results: All the prepared formulation was evaluated successfully. Out of all the formulations from each herbal oils the best two formulations were finalized, that is, $\mathrm{MO}_{2}$ and $\mathrm{CO}_{2}$ which show the greater in vitro diffusion rate among all. Formulation $\mathrm{MO}_{2}$ shows $55.45 \pm 0.10 \%$ and $\mathrm{CO}{ }_{2}$ showed $59.43 \pm 1.18 \%$ within $480 \mathrm{~min}$, respectively. Optimized formulations were also compared with the marketed formulation, which results in formulation $\mathrm{CO}_{2}$ as the best formulation among all.

Conclusion: It can be concluded that herbal oil-based cream proved better alternate than oral preparation and improve patient compliance, ease of administration, local bioavailability, and better proves for fungal infected patients.

Keywords: Itraconazole, Creams, Mustard oil, Olive oil, Mycoses.

(C) 2020 The Authors. Published by Innovare Academic Sciences Pvt Ltd. This is an open access article under the CC BY license (http://creativecommons. org/licenses/by/4. 0/) DOI: http://dx.doi.org/10.22159/ajpcr.2020.v13i11.39172

\section{INTRODUCTION}

Mycoses, a fungal infection of the skin caused by fungi, which are common and commonly minor. Two important types of infections, namely, superficial and subcutaneous fungal infection have been widely reported. Superficial fungal infections affect the superficial layer of the skin such as hair, nails, and especially in mucous membranes whereas subcutaneous infections involve a deeper layer of the skin. Numbers of disease caused by fungus are Aspergillus, blast mycosis, candidacies, and histoplasmosis [1,2]. In modern years, the incidence of these infections has increased steadily, mainly because of the rising number of immunocompromised patients and the growing status of health clubs and public swimming pools, which simplify the spread of infection $[3,4]$. The causes of fungal infection are generally accidental. Fungi often develop both virulence mechanisms and morphologic form, namely, yeasts and hyphae that simplify their reproduction within the host [5]. Tinea pedis, or athlete's foot, is a common condition and also is a disease that frequently is self-treated with over-the-counter preparations, often at the risk for recurrence and chronicity. Causal agents are dermatophyte species of the Trichophyton, Epidermophyton, and Microsporum genera [6]. Fungal infections occur progressively more in older adults. In general, tinea corporis and tinea cruris infection require once to twice-daily treatment for 2 weeks. Tinea pedis require treatment for 4 weeks. Several antifungal agents can be effectively used against these fungal infections, namely, fluconazole, miconazole, itraconazole, and sertaconazole [7-10].

The itraconazole is one of the effective antifungal agents against fungal infections which are used for the treatment of fungal infection in both HIV and non-HIV infected individuals. It is highly lipophilic as compared to the fluconazole and miconazole or practically insoluble in water [11]. Itraconazole is active against fungal infections such as aspergillosis, blastomycosis, histoplasmosis, as well as fungal infection restricted to the toenails and fingernails. The absorption of itraconazole from the gut is incomplete [12-15].
In the present study, the herbal oil-based herbal cream of itraconazole investigated for topical fungal infections. The herbal cream of itraconazole for fungal infection was prepared by using six different oils, namely, mustard oil (MO), olive oil (00), wheat germ oil (WGO), jojoba oil (JO), tea tree oil (TTO), and combined oil (CO). The different ingredients such as soft paraffin, cetyl alcohol, stearic acid, tween 80, and isopropyl myristate with different ratios and concentration were used to formulate the creams.

\section{MATERIALS AND METHODS}

Itraconazole drug was procured as a gift sample of Cipla Pvt Ltd., and all herbal oils; MO, 00, WGO, JO, and TTO were purchased from LobaChemicals Pvt Ltd. All other chemicals and solvents were used of Central Drug House ltd. All chemicals were used of analytical grades.

\section{Preformulation studies}

Preformulation studies include physical appearance, melting point, partition coefficient, solubility, identification of drug by UV spectroscopy, and Fourier transformed infrared (FTIR) spectroscopy. All the physical characterization was observed and compared with the standard monograph in official pharmacopoeia.

\section{Characterization of itraconazole by UV spectroscopy}

Characterization of itraconazole was performed in methanol by scanning the standard concentration of known drug solution in a range of $200-400 \mathrm{~nm}$ to find out the absorption maxima $\left(\lambda_{\text {max }}\right)$ of itraconazole.

\section{Preparation of the stock solution}

$10 \mathrm{mg}$ of itraconazole was accurately weighed and dissolved in $10 \mathrm{ml}$ of methanol to obtain a concentration of $1000 \mu \mathrm{g} / \mathrm{ml}$. Subsequently, $5 \mathrm{ml}$ was withdrawn from the above solution, and volume was made up to $100 \mathrm{ml}$ with methanol to get a $50 \mu \mathrm{g} / \mathrm{ml}$ solution. 
Preparation of working standard

A series of dilution of a standard solution containing $4-14 \mu \mathrm{g} / \mathrm{ml}$ itraconazole were prepared in methanol using a stock solution. The absorbance was measured at $262 \mathrm{~nm}$ against similarly treated blank using a UV spectrophotometer. The procedure was repeated 3 times and the average value of absorbance was calculated.

\section{FTIR study of itraconazole}

FTIR spectra of the pure drug were observed and analyzed by the potassium bromide $(\mathrm{KBr})$ press pellet method. Pure drug itraconazole was uniformly mixed with dry powdered $\mathrm{KBr}$ in the ratio of 1:100 and the mixture was then compressed into the transparent disk under high pressure using special dies. The disk was placed in the FTIR spectrophotometer and the spectrum was recorded. Spectrum was analyzing for the identification of the pure drug.

\section{Formulation of cream}

Creams were prepared using the trituration method, as the trituration method is the easiest method for the formulation of cream.

\section{Preparation of aqueous phase}

Glycerine, tween 80, EDTA, and isopropyl myristate were weighed properly and melted in a beaker. The temperature of the water phase is maintained between 65 and $70^{\circ} \mathrm{C}$

\section{Development of cream formulation}

The water portion was then slowly incorporated into the oil phase at $65-70^{\circ} \mathrm{C}$ and mixed for $10-15 \mathrm{~min}$. with continuous stirring. Then, the dispersion part was added into the above part slowly when the temperature reaches $40^{\circ} \mathrm{C}$. The $\mathrm{pH}$ of cream was kept between 5.8 and 6.8 .

\section{Optimization of oil for cream}

The various oils, namely, MOs, TTO, JO, WGO, 00, and CO are used to prepare the different formulation of itraconazole cream. In $\mathrm{CO}$ formulation, $10 \mathrm{ml}$ of stock solution of $\mathrm{CO}$ is prepared by using $2 \mathrm{ml}$ of each oil and different formulations were prepared (Tables 1 and 2).

\section{Evaluation of creams}

\section{Physical appearance}

Color, homogeneity, consistency, appearance, and texture were observed visually.

\section{pH of creams}

Creams $\mathrm{pH}$ was evaluated using a digital $\mathrm{pH}$ meter.

\section{Determination of the type of emulsion}

The determination of creams was done using the dye test. A minute amount of creams were used and a drop of dye was added to the cream. The creams were directly observed under the microscope at higher magnification to determine the type of emulsion [16].

\section{Content of uniformity}

$1 \mathrm{~g}$ of each formulation was taken in $100 \mathrm{ml}$ of volumetric flask and diluted with methanol. The sample was shaken properly until the whole sample was dissolved and finally makes up the solution with methanol. The solution was filtered and the filtrate was pipette out and diluted to $10 \mathrm{ml}$ with methanol. The sample was analyzed spectrophotometrically against a similarly treated blank at $\lambda_{\max } 262 \mathrm{~nm}$ [17].

\section{Viscosity}

The viscosity of cream was determined by Brookfield viscometer. The prepared formulation was poured into the adaptor of the viscometer and determined the viscosity of the test sample as per the standard operating procedure of viscometer. The spindle was rotated at speeds of $0.5,1,5,10$, and $20 \mathrm{rpm}$. At each speed, the corresponding dial reading on the viscometer was noted. The spindle speed was consecutively lowered and the corresponding dial reading was noted [18].

\section{Spreadability}

The spreadability of cream was determined by the apparatus, which consists of a wooden block, which was provided by a pulley at one end. By this method, spreadability was measured based on slip and drug characteristics of cream.

About $2 \mathrm{~g}$ cream was placed on the ground slide. Another slide was placed on that slide which has a dimension of a fixed ground slide and provided with the hook. $1 \mathrm{~kg}$ weighted was placed on the top of the two slides to provide a uniform film of the cream between the slides. The top plate was then subjected to a pull of $30 \mathrm{gm}$. With the help of string attached to the hook and the time (in seconds) required by the top slide to cover a distance of $7.5 \mathrm{~cm}$ be noted. A shorter interval indicates better spreadability $[19,20]$.

Spreadability was measured using the equation:

$S=M \times L / T$

Where, $M=$ Weight (gm) taken, $\mathrm{L}=$ Length of the slide, $\mathrm{T}=$ Time (s) taken.

\section{Determination of tube extrudability}

Creams were filled in a clean lacquered aluminum collapsible tube and pressed firmly at the crimped end. When the cap was removed, cream extruded until pressure dissipated. Weight in grams required to extrude a $0.5 \mathrm{~cm}$ ribbon of cream in $10 \mathrm{~s}$ was determined [21].

\section{In vitro diffusion study}

In vitro diffusion studies were carried out in a modified Franz diffusion cell. The receptor compartment was filled with saline phosphate buffer ( $\mathrm{pH}$ 7.4). The whole assembly was maintained at $37.0 \pm 1.0^{\circ} \mathrm{C}$ temperature and the receptor solution was stirred with a magnetic stirrer at $100 \mathrm{rpm}$ throughout the experiment. $1 \mathrm{ml}$ sample was withdrawn at regular intervals for $480 \mathrm{~min}$ and the withdrawn sample was replaced with an equal volume of fresh medium. The entire sample was suitably diluted with methanol and analyzed using a UV spectrophotometer at $264 \mathrm{~nm}$. After analyzing all the study of all formulations from different oils, the best-optimized formulation was evaluated based on in vitro diffusion studies. Optimized formulations were then compared with the marketed formulation $[22,23]$.

\section{RESULTS}

\section{Preformulation studies}

Preformulation studies for pure itraconazole were carried out to assess the physicochemical characters and compatibility of the drug.

\section{Characterization of itraconazole by UV spectroscopy}

Absorption maxima $\left(\lambda_{\max }\right)$ of itraconazole was determined in methanol in a UV spectrophotometer by scanning in a wavelength range of $400-200 \mathrm{~nm}$. $\lambda_{\max }$ of itraconazole was found to be $264 \mathrm{~nm}$ (Figs. 1 and 2 and Table 3).

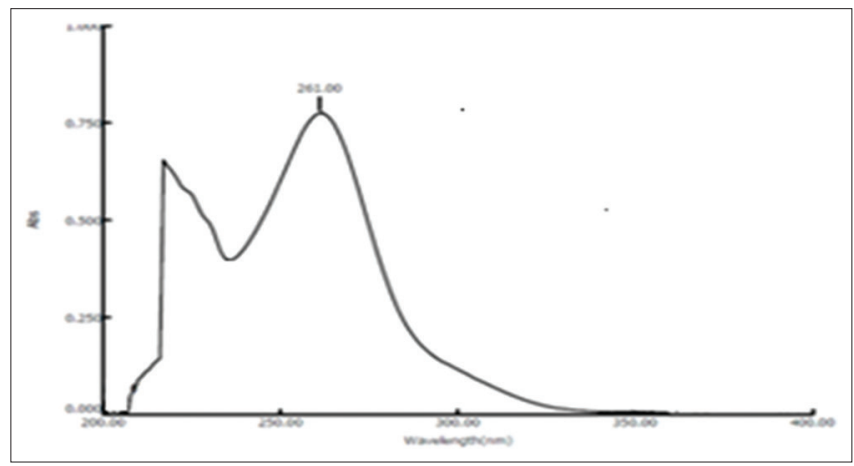

Fig. 1: Absorption maximum $\left(\lambda_{\max }\right)$ of itraconazole 


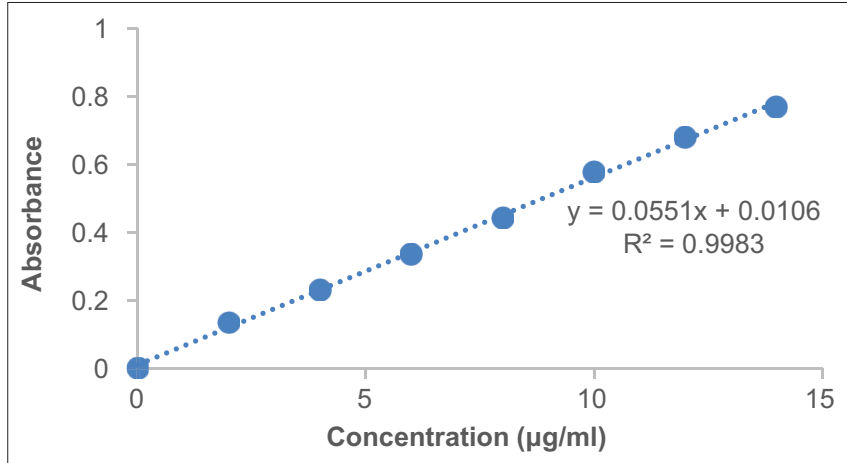

Fig. 2: Standard calibration curve of itraconazole
FTIR study of itraconazole

The FTIR spectrum of itraconazole discovered the presence of a peak at $783 \mathrm{~cm}^{-1}$ due to $\mathrm{C}-\mathrm{Cl}$ stretching; while peaks at $1627.92 \mathrm{~cm}^{-1}$ due to aromatic $\mathrm{C}=\mathrm{C}$ and $\mathrm{C}=\mathrm{N}$ stretching. A peek at $1274.94 \mathrm{~cm}^{-1}$ due to $\mathrm{C}-\mathrm{O}$ while peaks at $1699.29 \mathrm{~cm}^{-1}$ due to $\mathrm{C}=0$ and peak at $1334.74 \mathrm{~cm}^{-1}$ due to $\mathrm{C}$-N. As per the literature reported peaks, which further supports the purity of the drug (Fig. 3)

\section{Formulation of cream}

Cream of itraconazole was prepared by the trituration method and optimized for various parameters.

\section{Optimization of oils concentration}

The oil concentration was optimized in the range of $4-6 \%$. It was observed that as the concentration of oil was increased, viscosity of

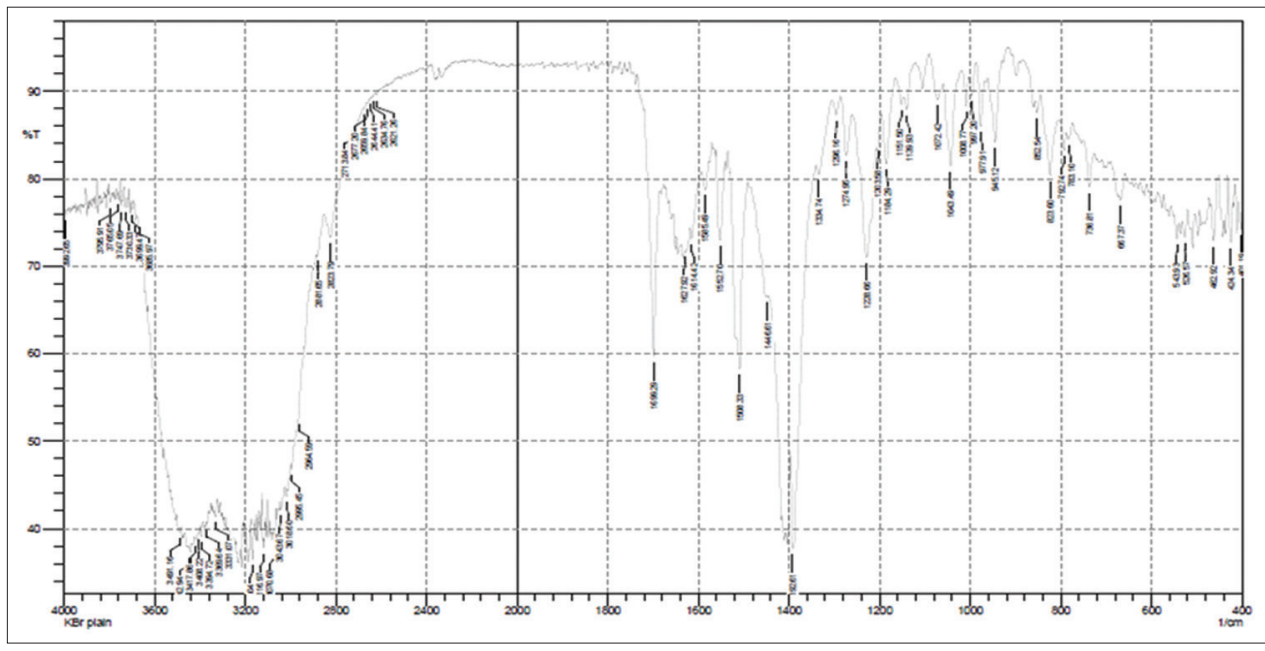

Fig. 3: FTIR spectra of itraconazole

Table 1: Optimized formulae of itraconazole herbal oil-based cream

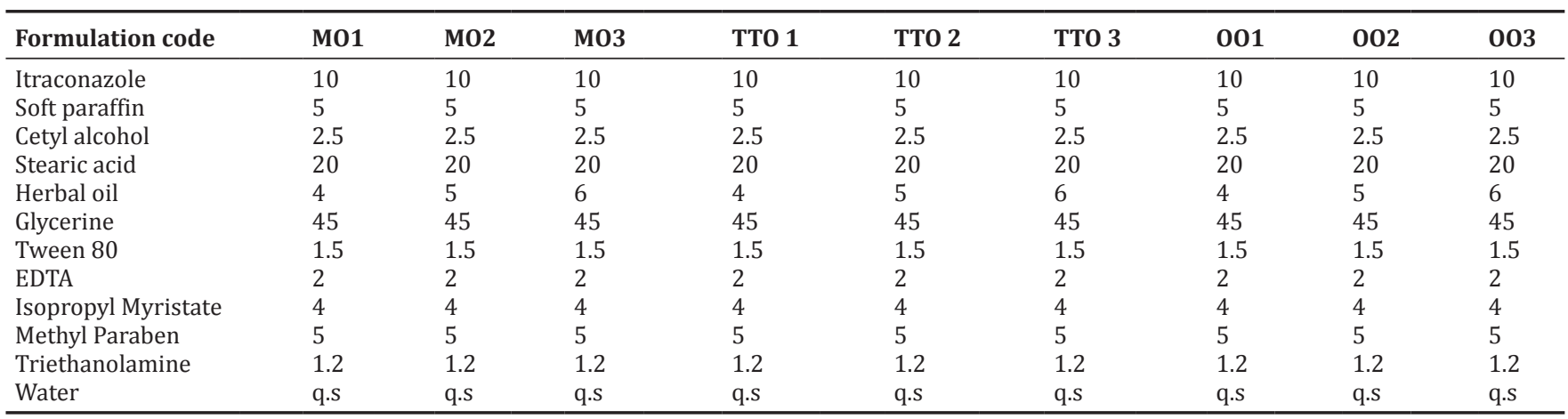

*MO: Mustard oil, TTO: Tea tree oil, 00: Olive oil, q.s: Quantity sufficient

Table 2: Optimized formulae of itraconazole herbal oil-based cream

\begin{tabular}{|c|c|c|c|c|c|c|c|c|c|}
\hline Formulation code & J01 & $\mathrm{J02}$ & $\mathrm{J03}$ & WG01 & WG02 & WG03 & CO1 & $\mathrm{CO} 2$ & $\mathrm{CO3}$ \\
\hline Itraconazole & 10 & 10 & 10 & 10 & 10 & 10 & 10 & 10 & 10 \\
\hline Soft paraffin & 5 & 5 & 5 & 5 & 5 & 5 & 5 & 5 & 5 \\
\hline Cetyl alcohol & 2.5 & 2.5 & 2.5 & 2.5 & 2.5 & 2.5 & 2.5 & 2.5 & 2.5 \\
\hline Stearic acid & 20 & 20 & 20 & 20 & 20 & 20 & 20 & 20 & 20 \\
\hline Herbal oil & 4 & 5 & 6 & 4 & 5 & 6 & 4 & 5 & 6 \\
\hline Glycerine & 45 & 45 & 45 & 45 & 45 & 45 & 45 & 45 & 45 \\
\hline Tween 80 & 1.5 & 1.5 & 1.5 & 1.5 & 1.5 & 1.5 & 1.5 & 1.5 & 1.5 \\
\hline Isopropyl Myristate & 4 & 4 & 4 & 4 & 4 & 4 & 4 & 4 & 4 \\
\hline Methyl Paraben & 5 & 5 & 5 & 5 & 5 & 5 & 5 & 5 & 5 \\
\hline Triethanolamine & 1.2 & 1.2 & 1.2 & 1.2 & 1.2 & 1.2 & 1.2 & 1.2 & 1.2 \\
\hline Water & q.s & q.s & q.s & q.s & q.s & q.s & q.s & q.s & q.s \\
\hline
\end{tabular}

*JO: Jojoba oil, WGO: Wheat germ oil, CO: Combined oil, q.s: Quantity sufficient 
cream was improved. The prepared cream was evaluated for various parameters, namely, physical appearance, $\mathrm{pH}$, drug content, viscosity, and spreadability. The physical appearance of all prepared cream is good and $\mathrm{pH}$ was found in the range of $6.14 \pm 0.02-7.4 \pm 0.04$. The type of emulsion of cream was found to w/o. The drug content of prepared cream was found to be $85.32 \pm 0.12 \%-96.42 \pm 0.12 \%$. The viscosities of different formulations were found to be in the range of $5498 \pm 42.21$ $8829 \pm 23.02 \mathrm{cp}$. Data are tabulated in Tables 4 and 5 .

\section{In vitro diffusion study}

In vitro release studies of the prepared cream formulations (M01M03, TT01-TT03, 001-003, J01-J03, WG01-WG03, and C01-C03) were done by Franz diffusion cell. Cumulative percent drug release of all formulations was between $42.11 \pm 1.21 \%$ and $59.43 \pm 1.18 \%$,

Table 3: Calibration curve of itraconazole

\begin{tabular}{|c|c|}
\hline Conc. $(\mu \mathrm{g} / \mathrm{ml})$ & Absorbance (mean $\pm S D, n=3$ ) \\
\hline 0 & 0 \\
\hline 2 & $0.135 \pm 004$ \\
\hline 4 & $0.231 \pm 0.002$ \\
\hline 6 & $0.335 \pm 0.004$ \\
\hline 8 & $0.444 \pm 0.001$ \\
\hline 10 & $0.578 \pm 0.002$ \\
\hline 12 & $0.68 \pm 0.003$ \\
\hline 14 & $0.77 \pm 0.001$ \\
\hline
\end{tabular}

respectively. Through, all the formulations $\mathrm{MO} 2$ and $\mathrm{CO} 2$ show the best in vitro drug release, that is, $55.45 \pm 1.10 \%$ and $59.43 \pm 1.18 \%$ within 480 min (Fig. 4). These two final formulations were further subjected to the comparison of the marketed formulation. Data are tabulated in Tables 6 and 7.

In vitro diffusion study for final formulation

The optimized final formulation (MO2 and $\mathrm{CO} 2$ ) was subjected to in vitro diffusion studies with the marketed formulation. The cumulative percent drug release of MO2 was $55.45 \pm 0.10 \%$, CO2 was $61.98 \pm 0.10 \%$, and the marketed formulation was $57.72 \pm 0.14 \%$ respectively. Therefore, from the data, formulation $\mathrm{CO} 2$ shows better results while comparing to the MO2 formulation as well as the marketed formulation. The results are shown in Table 8 .

\section{DISCUSSION}

Itraconazole herbal oil-based creams were prepared using different oils with their different optimized concentrations (4-6\%). Preformulation studies show purity and identification of the drug and all the data were with the specific limits. Different optimized formulations were prepared using different concentrations of oils. All the formulation exhibits good consistency and good tube extrudability [18,19]. The drug content of all the formulations was within the standard limits. The spreadability of all the formulation was between $6.11 \pm 0.13$ and $9.76 \pm 0.31 \mathrm{~cm}$ (Tables 4 and 5). Formulation $\mathrm{JO}_{2}$ shows the highest spreadability; $9.76 \pm 0.31 \mathrm{~cm}$ and formulation $\mathrm{CO}_{2}$ shows the highest
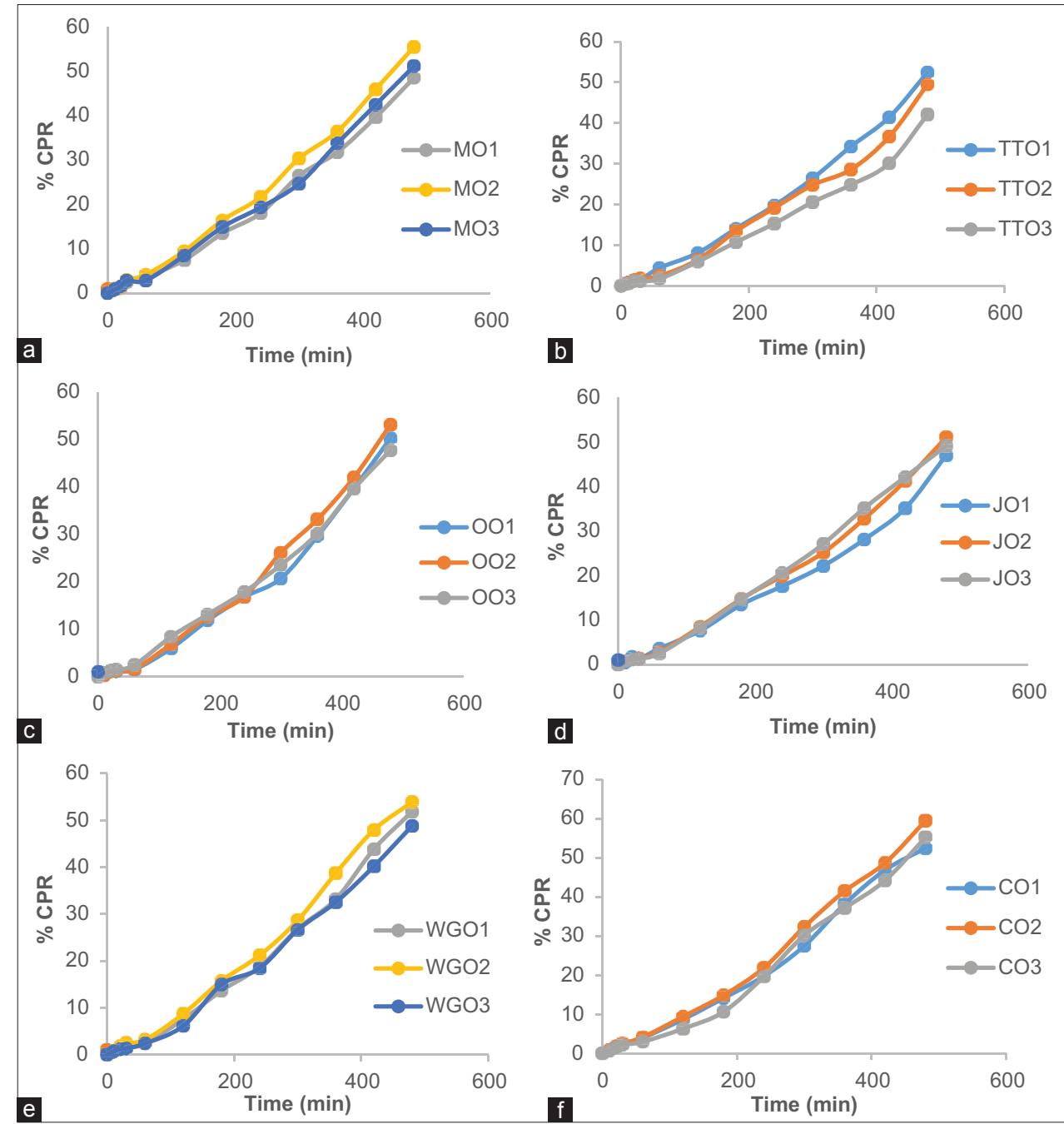

Fig. 4: In vitro diffusion study of different formulations (a) mustard oil, (b) tea tree oil, (c) olive oil, (d) jojoba oil, (e) wheat germ oil, (f) combined oil 
Table 4: Evaluation parameter for optimized formulation

\begin{tabular}{|c|c|c|c|c|c|c|c|c|c|}
\hline Parameters & M01 & M02 & M03 & TT01 & TT02 & TT03 & 001 & 002 & 003 \\
\hline Color & Light yellow & Light yellow & Light yellow & ight yellow & Light yellow & Light yellow & White & White & Whi \\
\hline Feel & Not smooth & Smooth & Smooth & Not smooth & Smooth & Smooth & Smooth & Smooth & Smooth \\
\hline Consistency & Not good & Good & Good & Not good & Good & Good & Not good & Good & Good \\
\hline $\mathrm{pH}$ & $6.27 \pm 0.03$ & $6.50 \pm 0.01$ & $6.29 \pm 0.04$ & $6.31 \pm 0.04$ & $6.58 \pm 0.01$ & $6.41 \pm 0.01$ & $6.25 \pm 0.02$ & $6.61 \pm 0.01$ & $6.14 \pm 0.02$ \\
\hline$\%$ Drug content & $92.32 \pm 0.14$ & $91.32 \pm 0.11$ & $86.34 \pm 0.10$ & $89.52 \pm 0.13$ & $91.14 \pm 0.13$ & $85.32 \pm 0.12$ & $88.34 \pm 0.14$ & $92.23 \pm 0.12$ & $89.44 \pm 0.09$ \\
\hline Spreadability $(\mathrm{cm})$ & $6.45 \pm 0.13$ & $9.17 \pm 0.12$ & $7.15 \pm 0.18$ & $6.48 \pm 0.10$ & $8.49 \pm 0.11$ & $7.24 \pm 0.24$ & $7.16 \pm 0.21$ & $8.43 \pm 0.13$ & $7.11 \pm 0.04$ \\
\hline Tube extrudability & Good & Excellent & Good & Good & Good & Good & Good & Excellent & Good \\
\hline
\end{tabular}

${ }^{*}$ mean \pm SD, n=3, SD: Standard deviation, cp: Centipoise, cm: Centimeter, MO: Mustard oil, TTO: Tea tree oil, o0: Olive oil

Table 5: Evaluation parameter for optimized formulation

\begin{tabular}{|c|c|c|c|c|c|c|c|c|c|}
\hline Parameters & J01 & J02 & J03 & WG01 & WG02 & WG03 & Co1 & $\mathrm{CO} 2$ & $\mathrm{CO3}$ \\
\hline Color & White & White & White & White & Vhit & White & Light yellow & Light yellow & Light yellow \\
\hline Feel & Smooth & Smooth & Smooth & Not smooth & Smooth & Smooth & Smooth & Smooth & Smooth \\
\hline Consistency & Good & Good & Good & Not good & Good & Good & Good & Good & Good \\
\hline $\mathrm{pH}$ & $6.5 \pm 0.02$ & $6.8 \pm 0.02$ & $7.4 \pm 0.04$ & $7.2 \pm 0.03$ & $6.5 \pm 0.01$ & $7.4 \pm 0.02$ & $7.4 \pm 0.03$ & $6.7 \pm 0.01$ & $7.2 \pm 0.04$ \\
\hline Drug content & $91.41 \pm 0.01$ & $95.44 \pm 0.14$ & $89.53 \pm 0.12$ & $88.52 \pm 0.11$ & $94.72 \pm 0.23$ & $91.42 \pm 0.12$ & $91.41 \pm 0.30$ & $96.42 \pm 0.12$ & $89.42 \pm 0.22$ \\
\hline Spreadability (cm) & $6.11 \pm 0.13$ & $9.76 \pm 0.31$ & $8.43 \pm 0.53$ & $7.54 \pm 0.11$ & $8.71 \pm 0.21$ & $8.32 \pm 0.14$ & $7.16 \pm 0.13$ & $9.23 \pm 023$ & $8.19 \pm 0.11$ \\
\hline Tube extrudability & Good & Good & Good & Good & Good & Good & Good & Excellent & Good \\
\hline
\end{tabular}

${ }^{*}$ mean \pm SD, n=3, SD: Standard deviation, cp: Centipoise, $\mathrm{cm}$ : Centimeter, JO: Jojoba oil, WGO: Wheat germ oil, CO: Combined oil

Table 6: In vitro diffusion study of optimized formulations

\begin{tabular}{|c|c|c|c|c|c|c|c|c|c|}
\hline \multirow[t]{2}{*}{ Time (min) } & M01 & MO2 & M03 & TT01 & TT02 & TT03 & 001 & 002 & 003 \\
\hline & \multicolumn{9}{|c|}{$\%$ cumulative drug release } \\
\hline 0 & 0 & 0 & 0 & 0 & 0 & 0 & 0 & 0 & 0 \\
\hline 10 & $0.69 \pm 1.12$ & $0.98 \pm 1.16$ & $0.78 \pm 1.23$ & $0.82 \pm 1.11$ & $0.73 \pm 1.12$ & $0.56 \pm 1.12$ & $0.24 \pm 1.23$ & $0.39 \pm 1.16$ & $0.77 \pm 1.20$ \\
\hline 20 & $1.16 \pm 1.18$ & $1.29 \pm 1.17$ & $1.45 \pm 1.12$ & $1.19 \pm 1.14$ & $1.42 \pm 1.14$ & $1.2 \pm 1.24$ & $1.19 \pm 1.25$ & $1.06 \pm 1.18$ & $1.27 \pm 1.19$ \\
\hline 30 & $2.38 \pm 1.11$ & $2.95 \pm 1.12$ & $2.82 \pm 1.14$ & $1.42 \pm 1.15$ & $1.89 \pm 1.11$ & $1.19 \pm 1.21$ & $1.14 \pm 1.14$ & $1.24 \pm 1.18$ & $1.49 \pm 1.12$ \\
\hline 60 & $3.65 \pm 1.14$ & $4.17 \pm 1.10$ & $2.85 \pm 1.12$ & $4.45 \pm 1.15$ & $2.49 \pm 1.12$ & $1.77 \pm 1.12$ & $1.52 \pm 1.9$ & $1.62 \pm 1.20$ & $2.45 \pm 1.18$ \\
\hline 120 & $7.45 \pm 1.15$ & $9.45 \pm 1.14$ & $8.48 \pm 1.11$ & $8.12 \pm 1.16$ & $6.45 \pm 1.15$ & $5.98 \pm 1.12$ & $5.98 \pm 1.20$ & $6.86 \pm 1.25$ & $8.43 \pm 1.15$ \\
\hline 180 & $13.49 \pm 1.12$ & $16.42 \pm 1.17$ & $14.89 \pm 1.17$ & $14.11 \pm 1.12$ & $13.51 \pm 1.14$ & $10.79 \pm 1.18$ & $11.86 \pm 1.11$ & $12.64 \pm 1.19$ & $13.11 \pm 1.14$ \\
\hline 240 & $18.04 \pm 1.12$ & $21.67 \pm 1.11$ & $19.32 \pm 1.15$ & $19.76 \pm 1.10$ & $19.18 \pm 1.18$ & $15.35 \pm 1.18$ & $16.78 \pm 1.18$ & $16.85 \pm 1.28$ & $17.84 \pm 1.21$ \\
\hline 300 & $26.45 \pm 1.10$ & $30.34 \pm 1.10$ & $24.65 \pm 1.10$ & $26.42 \pm 1.09$ & $24.81 \pm 1.19$ & $20.61 \pm 1.17$ & $20.71 \pm 1.25$ & $26.11 \pm 1.24$ & $23.56 \pm 1.24$ \\
\hline 360 & $31.75 \pm 1.15$ & $36.41 \pm 1.09$ & $33.75 \pm 1.12$ & $34.26 \pm 1.09$ & $28.61 \pm 1.21$ & $24.85 \pm 1.19$ & $29.61 \pm 1.27$ & $33.17 \pm 1.21$ & $30.14 \pm 1.22$ \\
\hline 420 & $39.65 \pm 1.14$ & $45.91 \pm 0.21$ & $42.44 \pm 1.14$ & $41.45 \pm 1.13$ & $36.68 \pm 1.25$ & $30.17 \pm 1.19$ & $39.68 \pm 1.11$ & $41.98 \pm 1.22$ & $39.61 \pm 1.16$ \\
\hline 480 & $48.49 \pm 1.16$ & $55.45 \pm 0.10$ & $51.11 \pm 1.15$ & $52.43 \pm 1.11$ & $49.51 \pm 1.21$ & $42.11 \pm 1.21$ & $50.24 \pm 1.16$ & $53.11 \pm 1.17$ & $47.73 \pm 1.10$ \\
\hline
\end{tabular}

*mean \pm SD, n=3, SD: Standard deviation, MO: Mustard oil, TTO: Tea tree oil, O0: Olive oil

Table 7: In vitro diffusion study of optimized formulations

\begin{tabular}{|c|c|c|c|c|c|c|c|c|c|}
\hline \multirow[t]{2}{*}{ Time (min) } & J01 & J02 & J03 & WG01 & WG02 & WG03 & Co1 & $\mathrm{CO} 2$ & CO3 \\
\hline & \multicolumn{9}{|c|}{$\%$ cumulative drug release } \\
\hline 0 & 0 & 0 & 0 & 0 & 0 & 0 & 0 & 0 & 0 \\
\hline 20 & $1.75 \pm 1.12$ & $1.18 \pm 1.24$ & $1.15 \pm 1.18$ & $1.13 \pm 1.22$ & $1.78 \pm 1.10$ & $1.18 \pm 1.15$ & $1.62 \pm 1.15$ & $1.79 \pm 1.18$ & $1.58 \pm 1.14$ \\
\hline 30 & $1.26 \pm 1.20$ & $1.42 \pm 1.18$ & $1.26 \pm 1.19$ & $1.37 \pm 1.10$ & $2.52 \pm 1.18$ & $1.33 \pm 1.10$ & $2.33 \pm 1.15$ & $2.62 \pm 1.13$ & $2.21 \pm 1.11$ \\
\hline 60 & $3.58 \pm 1.10$ & $2.76 \pm 1.14$ & $2.48 \pm 1.20$ & $2.41 \pm 1.18$ & $3.16 \pm 1.15$ & $2.39 \pm 1.14$ & $3.98 \pm 1.24$ & $4.15 \pm 1.21$ & $2.98 \pm 1.19$ \\
\hline 120 & $7.63 \pm 1.18$ & $8.52 \pm 1.15$ & $8.21 \pm 1.11$ & $7.54 \pm 1.16$ & $8.72 \pm 1.21$ & $6.14 \pm 1.18$ & $8.72 \pm 1.18$ & $9.42 \pm 1.11$ & $6.33 \pm 1.14$ \\
\hline 180 & $13.48 \pm 1.16$ & $14.78 \pm 1.12$ & $14.65 \pm 1.15$ & $13.65 \pm 1.14$ & $15.74 \pm 1.26$ & $14.94 \pm 1.10$ & $14.12 \pm 1.11$ & $14.85 \pm 1.18$ & $10.62 \pm 1.13$ \\
\hline 240 & $17.63 \pm 1.14$ & $19.92 \pm 1.11$ & $20.63 \pm 1.11$ & $18.72 \pm 1.22$ & $21.18 \pm 1.15$ & $18.43 \pm 1.19$ & $19.75 \pm 1.17$ & $21.86 \pm 1.19$ & $19.63 \pm 1.20$ \\
\hline 300 & $22.18 \pm 2.02$ & $25.17 \pm 1.10$ & $27.12 \pm 1.12$ & $26.85 \pm 1.19$ & $28.65 \pm 1.28$ & $26.62 \pm 1.15$ & $27.47 \pm 1.14$ & $32.32 \pm 1.20$ & $30.17 \pm 1.24$ \\
\hline 360 & $28.14 \pm 1.14$ & $32.81 \pm 1.14$ & $35.17 \pm 1.15$ & $33.18 \pm 1.14$ & $38.71 \pm 1.10$ & $32.53 \pm 1.20$ & $38.16 \pm 1.20$ & $41.46 \pm 1.24$ & $37.13 \pm 1.22$ \\
\hline 420 & $35.16 \pm 1.11$ & $41.32 \pm 1.11$ & $42.18 \pm 1.22$ & $43.85 \pm 1.17$ & $47.95 \pm 1.14$ & $40.21 \pm 1.17$ & $46.83 \pm 1.22$ & $48.65 \pm 1.17$ & $44.18 \pm 1.10$ \\
\hline 480 & $47.11 \pm 1.19$ & $51.09 \pm 1.17$ & $49.21 \pm 1.28$ & $51.85 \pm 1.15$ & $53.89 \pm 1.27$ & $48.81 \pm 1.13$ & $52.45 \pm 1.19$ & $59.43 \pm 1.18$ & $55.16 \pm 1.17$ \\
\hline
\end{tabular}

*mean \pm SD, n=3, SD: Standard deviation, JO: Jojoba oil, WGO: Wheat germ oil, CO: Combined oil

viscosity of $8829 \pm 23.02 \mathrm{cp}$. In vitro diffusion studies were performed using a modified Franz diffusion cell. All the data are shown in Tables 6 and 7. Formulation $\mathrm{MO}_{2}$ and $\mathrm{CO}_{2}$ shows the highest percent drug release rest of all. $\mathrm{MO}_{2}$ shows $55.45 \pm 0.10 \%$ and $\mathrm{CO}_{2}$ shows $59.43 \pm 1.18 \%$ drug release [23]. Both the final formulations were subject further diffusion study with the marketed formulation and found that formulation $\mathrm{CO}_{2}$ was the best formulation among two and shows a percent drug release of $61.98 \pm 1.10 \%$ (Table 8 and Fig. 5). 


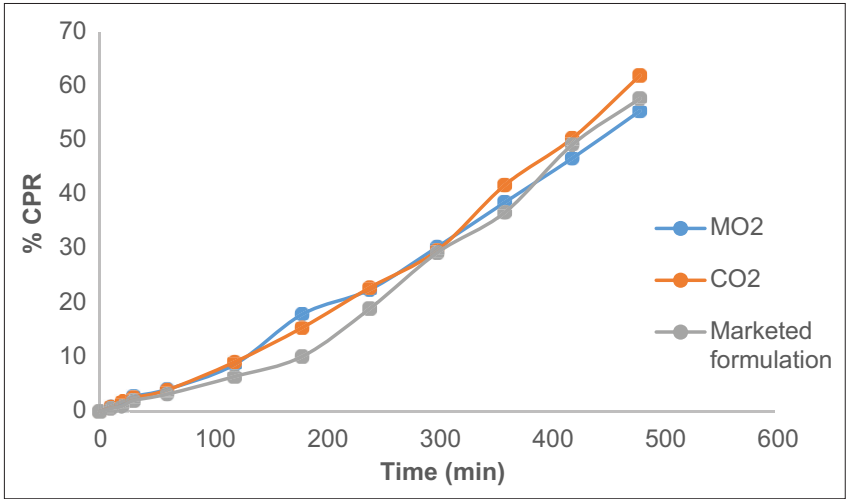

Fig. 5: Comparison of drug release profile of final formulations (M02 and C02) with marketed formulation

Table 8: In vitro diffusion study for final formulations (MO2 and C02) with marketed formulation

\begin{tabular}{llll}
\hline \multirow{2}{*}{ Time (min) } & $\mathbf{M O}_{2}$ & $\mathbf{C O}_{2}$ & Marketed formulation \\
\cline { 2 - 4 } & \multicolumn{3}{l}{ \% cumulative drug release } \\
\hline 0 & 0 & 0 & 0 \\
10 & $0.88 \pm 1.12$ & $0.84 \pm 1.15$ & $0.55 \pm 1.13$ \\
20 & $1.49 \pm 1.13$ & $1.81 \pm 1.14$ & $0.97 \pm 1.09$ \\
30 & $2.75 \pm 1.16$ & $2.52 \pm 1.10$ & $1.99 \pm 1.10$ \\
60 & $4.07 \pm 1.12$ & $3.95 \pm 1.09$ & $3.18 \pm 1.18$ \\
120 & $8.65 \pm 1.12$ & $9.12 \pm 1.06$ & $6.44 \pm 1.14$ \\
180 & $17.92 \pm 1.14$ & $15.45 \pm 1.08$ & $10.13 \pm 1.14$ \\
240 & $22.47 \pm 1.13$ & $22.84 \pm 1.10$ & $18.96 \pm 1.12$ \\
300 & $30.34 \pm 1.11$ & $29.69 \pm 1.12$ & $29.29 \pm 1.13$ \\
360 & $38.58 \pm 1.10$ & $41.76 \pm 1.11$ & $36.71 \pm 1.15$ \\
420 & $46.72 \pm 1.08$ & $50.41 \pm 1.10$ & $49.22 \pm 1.16$ \\
480 & $55.45 \pm 1.10$ & $61.98 \pm 1.10$ & $57.72 \pm 1.14$ \\
\hline
\end{tabular}

*mean \pm SD, $n=3$, SD: Standard deviation, MO: Mustard oil, CO: Combined oil

\section{CONCLUSION}

The herbal oil-based creams were prepared by the trituration method. Six herbal oils were used, namely, MO, OO, JO, TTO, WGO, and CO. Each oil was formulated different formulations with different ratio of oils. Preformulation data were within the specified limits. From the complete discussion, it was concluded that $\mathrm{CO}_{2}$ is the best formulation among all. The various parameters of $\mathrm{CO}_{2}$ formulation were found, namely, drug content was $95.55 \pm 0.12 \%$, viscosity was $8419 \pm 42.61 \mathrm{cps}$, spreadability was $8.23 \pm 0.13 \mathrm{~cm}$ excellent tube extrudability, and percent drug release was $59.43 \pm 1.18 \%$ within 480 min which was greater than rest of the formulations. Hence, herbal oil-based cream of itraconazole improves patient compliance, ease of administration, local bioavailability, and better prove for fungal infected patients.

\section{AUTHORS' CONTRIBUTIONS}

All the author have contributed equally.

\section{CONFLICTS OF INTEREST}

None.

\section{AUTHORS FUNDING}

None.

\section{REFERENCES}

1. Pfaller MA, Sutton DA. Review of in vitro activity of sertaconazole nitrate in the treatment of superficial fungal infections. Diagn Microbiol Infect Dis 2006;56:147-52.

2. Walsh TJ, Dixon DM, Baron S. Spectrum of mycoses. In: Medicinal Microbiology. $4^{\text {th }}$ ed., Ch. 75. Galveston, TX: University of Texas Medical Branch at Galveston; 1996.

3. Detandt M, Nolard N. Fungal contamination of the floors of swimming pools, particularly subtropical swimming paradises. Mycoses 1995;38:509-13.

4. Garber G. An overview of fungal infections. Drugs 2001;61:1-12.

5. Márquez M, Camps F. Sertaconazole in the treatment of mycoses: From dermatology to gynecology. Int J Gynecol Obstet 2000;71:S3-20.

6. Meis JF, Verweij PE. Current management of fungal infections. Drugs 2001;61:13-25.

7. Carrillo-Muñoz AJ, Giusiano G, Ezkurra PA. Sertaconazole: Updated review of a topical antifungal agent. Expert Rev Anti Infect Ther 2005;3:333-42.

8. Weinstein A, Berman B. Topical treatment of common superficial tinea infections. Am Fam Physician 2002;65:2095-102.

9. Kelly BP. Superficial fungal infections. Pediatr Rev 2012;33:e22-37.

10. Nicola Salmon MR, Claire Fuller MA, Federal Rules of Civil Procedure. Fungal skin infections: Current approaches to management. Drug Rev 2013;26:31-5.

11. Grant SM, Clissold SP. Itraconazole. A review of its pharmacodynamic and pharmacokinetic properties, and therapeutic use in superficial and systemic mycoses. Drugs 1989;37:310-44.

12. Piérard G, Arrese J, Piérard-Franchimont C. Itraconazole. Expert Opin Pharmacother 2000;1:287-304.

13. De Doncker P, Pande S, Richarz U, Garodia N. Itraconazole: What clinicians should know? Indian J Drugs Dermatol 2017;3:4-10.

14. Tsai YC, Tsai TF. Itraconazole in the treatment of nonfungal cutaneous diseases: A review. Dermatol Ther (Heidelb) 2019;9:271-80.

15. Lestner J, Hope WW. Itraconazole: An update on pharmacology and clinical use for treatment of invasive and allergic fungal infections. Expert Opin Drug Metab Toxicol 2013;9:911-26.

16. Sheth H, Desai S, Patel D, Patel D, Patel P, Patel S, et al. Formulation and evaluation of topical herbal cream for cellulitis. J Pharm Sci Biosci Res 2016;6:584-93.

17. Chen MX, Alexander KS, Baki G. Formulation and evaluation of antibacterial creams and gels containing metal ions for topical application. J Pharm (Cairo) 2016;2016:5754349.

18. Maha HL, Sinaga KM, Masfria M. Formulation and evaluation of miconazole nitrate nanoemulsion and cream. Asian J Pharm Clin Res 2018;11:319-21.

19. Kasar MP, Kale K, Phadtare GD. Formulation and evaluation of topical antifungal gel containing itraconazole. Int J Curr Pharm Res 2018;10:71-4.

20. Maru AD, Lahoti SR. Formulation and evaluation of moisturizing cream containing sunflower wax. Int J Pharm Pharm Sci 2018;10:54-9.

21. Premkumar A, Muthukumaran T, Ganeshan V, Shanmugam R, Lalitha PD. Formulation and evaluation of cream containing antifungal agents, antibacterial agents and corticosteroids. Hygeia J D Med 2014;6:5-16.

22. Sabale V, Kunjwani H, Sabale P. Formulation and in vitro evaluation of the topical antiageing preparation of the fruit of Benincasa hispida. J Ayurveda Integr Med 2011;2:124-8.

23. Debebe D, Gabriel T, Brhane Y, Temesgen A, Nigatu M, Marew T. Comparative in vitro evaluation of brands of clotrimazole cream formulations marketed in Ethiopia. J Drug Deliv Ther 2018;8:17-2. 